\title{
Uranium Characterization at the St. Louis Airport Site
}
A. I. Schilk
C. W. Hubbard
R. T. Reiman
T. W. Bowyer

May 1995

Prepared for the U.S. Department of Energy's Office of Technology Development under Contract DE-AC06-76RLO 1830

Pacific Northwest Laboratory Operated for the U.S. Department of Energy by Battelle Memorial Institute 


\section{DISCLAIMER}

This report was prepared as an account of work sponsored by an agency of the United States Government. Neither the United States Government nor any agency. thereof, nor Battelle Memorial Institute, nor any of their employees, makes any warranty, expressed or implied, or assumes any legal liability or responsibility for the accuracy, completeness, or usefulness of any information, apparatus, product, or process disclosed, or represents that its use would not infringe privately owned rights. Reference herein to any specific commercial product, process; or service by trade name, trademark, manufacturer, or otherwise does not necessarily constitute or imply its endorsement, recommendation, or favoring by the United States Government or any agency thereof, or Battelle-Memorial Institute. The views and opinions of authors expressed herein do not necessarily state or reflect those of the United States Government or any agency thereof.

\section{PACIFIC NORTHWEST LABORATORY operated by \\ BATTELLE MEMORIAL INSTITUTE for the \\ UNITED STATES DEPARTMENT OF ENERGYY under Contract DE-ACO6-Z6RLO 1830}

Printed in the United States of America

Available to DOE and DOE contractors from the

Office of Scientific and Technical Information, P.O. Box 62, Oak Ridge, TN 37831 . prices available from (615) 576-8401. FTS 626-8401.

Available to the public from the National Technical Information/Service, U.S. Department of Commerce, 5285 Port Royal Rd, Springfield, VA 22161. 
PNL-10534

UC-606

\title{
Uranium Characterization at the St. Louis Airport Site
}

\author{
A.J. Schilk \\ C.W. Hubbard \\ R.T. Reiman' \\ T.W. Bowyer
}

May 1995

Prepared for the U.S. Department of Energy

under Contract DE-AC06-76RLO 1830

Pacific Northwest Laboratory

Richland, Washington 99352

'Technical Measurement Company, Boulder, Colorado 



\section{DISCLAIMER}

Portions of this document may be illegible in electronic image products. Images are produced from the best available original document. 


\section{Executive Summary}

In support of the Department of Energy/Office of Technology Development's Expedited Site Characterization (ESC) project (coordinated by Ames Laboratory), the Pacific Northwest Laboratory demonstrated two complementary technologies at the St. Louis Airport (SLAP) site that have been designed and optimized for the rapid, in situ quantification of radionuclide contamination in surface soils. The sensors are optimized for the detection of high-energy beta particles or gamma rays emitted from the decay of specific radionuclides of interest.

These technologies were demonstrated by measuring the beta and gamma fluxes at several locations within the SLAP site. Measurements were converted to average contamination levels, using detector calibrations performed with spiked samples (beta) or sealed sources (gamma). Additionally, subsurface activity levels were derived from discrete soil samples (provided by the ESC field crew) via gamma-ray spectrometry in a controlled laboratory setting.

Since the beta and gamma sensor technologies are intrinsically sensitive to different types of radiation and activity distributions (i.e., surface and shallow subsurface, respectively), the data obtained from the two detectors provide complementary information about the distribution of the contamination. The results reported here suggest that a number of locations within the SLAP site have elevated levels of ${ }^{238} U$, and the differences between the beta and gamma activities indicate that the contamination is largely located near the surface of the soil. 



\section{Contents}

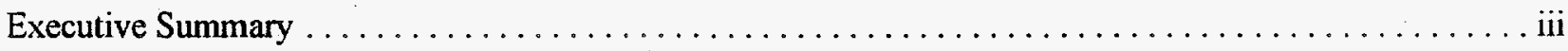

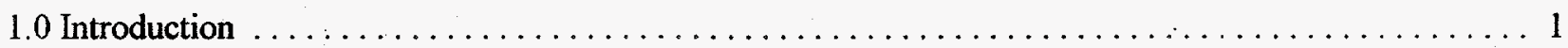

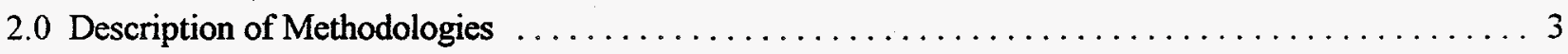

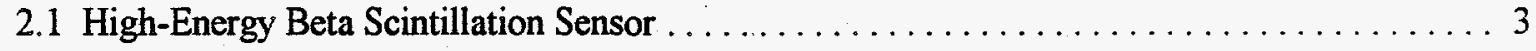

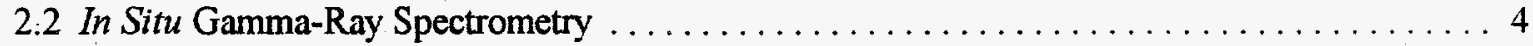

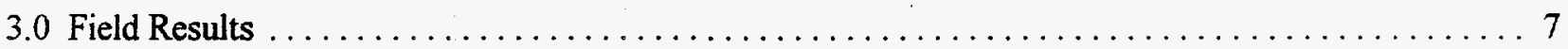

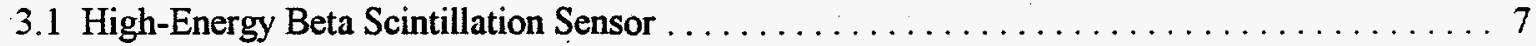

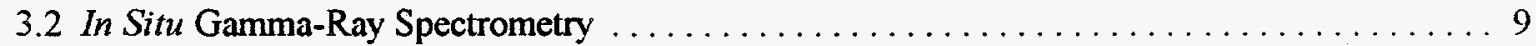

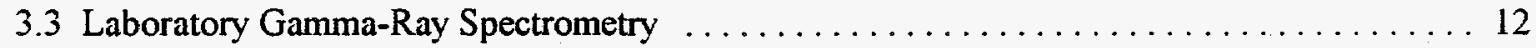

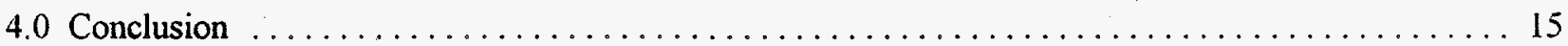

\section{Figures}

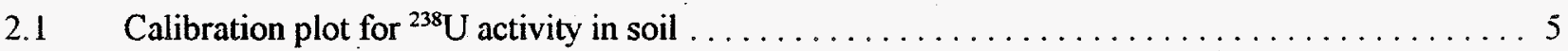

3.1 Plot of calculated ${ }^{214} \mathrm{Bi}$ activities versus associated gamma-ray energy based on the assumption of a uniformly distributed source. The monotonically increasing trend implies that the source is actually shielded from the sensor and, perhaps, is buried at this location (flag \#5)

\section{Tables}

3.1 Results from the daily background measurements $\ldots \ldots \ldots \ldots \ldots \ldots \ldots \ldots \ldots \ldots$

3.2 Results from the high-energy beta scintillation sensor $\ldots \ldots \ldots \ldots \ldots \ldots \ldots \ldots \ldots \ldots \ldots$

3.3 Results from in situ gamma-ray spectrometry $\ldots \ldots \ldots \ldots \ldots \ldots \ldots \ldots \ldots \ldots \ldots \ldots$

$3.4 \quad$ Results from laboratory gamma-ray spectrometry $\ldots \ldots \ldots \ldots \ldots \ldots \ldots \ldots \ldots \ldots$ 


\subsection{Introduction}

The Department of Energy has made a broad commitment to sponsor environmental characterization and remediation efforts at former sites that are known or suspected to be contaminated with radionuclides. One such site is located adjacent to the St. Louis International Airport, where uranium processing wastes were stored during the 1940s and 1950s. In support of establishing remedial protocols for this defunct facility, Ames Laboratory's Expedited Site Characterization Project has been tasked with the oversight of field evaluations for various in situ detection methodologies.

Toward this end, the Pacific Northwest Laboratory ${ }^{(a)}$ demonstrated two complementary technologies that have been designed and optimized for the rapid, in situ quantification of radionuclide contamination in surface soils. One system employs a vertical array of scintillating optical fibers for detecting high-energy beta particles emitted from the decay of uranium in surficial materials. The second system is capable of probing both surface and shallow subsurface radionuclide distributions (in situ and ex situ) by detecting their characteristic gamma rays with a high-purity germanium crystal.

In this paper, we briefly describe the theories of operation for these detection methodologies, their calibration procedures, and field operations at the St. Louis site. We also present and compare the results from these disparate technologies and offer an interpretation of the soil-contamination scenario based on this limited investigation.

(a)Pacific Northwest Laboratory is operated for the U.S. Department of Energy by Battelle Memorial Institute under contract DE-AC06-76RLO 1830. 



\subsection{Description of Methodologies}

\subsection{High-Energy Beta Scintillation Sensor}

A traditional technique for detecting charged particles (e.g., betas) uses a material that scintillates, or emits light, when such species pass through that medium. The resulting scintillation light may then be used to indicate the presence of these charged particles or, since the amount of scintillation light is proportional to the energy deposited by the charged particle, their relative energies as well. For example, polystyrene-based plastic fibers may be doped during their casting process with various fluorescent compounds that have been carefully selected to produce the desired scintillation, optical, and radiation-resistance characteristics necessary for the technical requirements. Charged particles passing through these individual fibers ionize and excite the fluorescent dopants, which subsequently de-excite via the emission of visible light. The resulting light pulses are then partially transmitted down the length of the fiber and can be converted into electrical signals via a light-sensitive device such as a photo-multiplier tube. The intensities of these charge pulses are directly proportional to the total light transmitted through the fiber and, consequently, the energy deposited per event.

An innovative sensor composed of 0.5 -mm-thick and $1.0-\mathrm{mm}$-thick plastic scintillating fibers has been designed to be placed directly on or above contaminated soil to observe high-energy beta particles that originate from the decay chain of uranium. Strictly speaking, this sensor indirectly detects uranium activity, based on the assumption that secular equilibrium exists between the parent radionuclide and its daughter:

$$
\begin{aligned}
& { }^{238} \mathrm{U}\left(4.47 \times 10^{9} \mathrm{y}\right) \rightarrow{ }^{234} \mathrm{Th}(24.1 \mathrm{~d}) \rightarrow{ }^{234 \mathrm{~m}} \mathrm{~Pa}(1.18 \mathrm{~m}) \rightarrow{ }^{234} \mathrm{U}\left(2.45 \times 10^{5} \mathrm{y}\right) \rightarrow \\
& \left.{ }^{230} \mathrm{Th}\left(7.54 \times 10^{4} \mathrm{y}\right) \rightarrow{ }^{226} \mathrm{Ra}\left(1.60 \times 10^{3} \mathrm{y}\right) \rightarrow(\text { (radon+daughters }) \rightarrow{ }^{206} \mathrm{~Pb} \text { (stable }\right) .
\end{aligned}
$$

Such a condition may not occur for 5 or 6 months following initial production (or any fractionation process in which parent and daughter are separated) due to the relatively long-lived intermediary, ${ }^{234} \mathrm{Th}$. However, with regard to contaminated soils associated with existing DOE facilities, the assumption of secular equilibrium is valid in most, if not all, cases, and the detected activity of the daughter is essentially equivalent to that of the parent isotope. This sensor employs a vertically stacked configuration of fiber ribbons that determines the penetration depths of incident charged particles and allows discrimination between the unattenuated betas from ${ }^{234 m \mathrm{~Pa}}$ (a decay daughter of ${ }^{238} \mathrm{U}$ ) and lower-energy beta particles arising typically from natural sources (namely, other ${ }^{238} \mathrm{U}$ daughters, ${ }^{232} \mathrm{Th}$ and its daughters, and ${ }^{40} \mathrm{~K}$ ).

A $2.29-\mathrm{MeV}$ maximum-energy beta particle is associated with $98 \%$ of all ${ }^{234 m} \mathrm{~Pa}$ decays. When traveling normally incident to the sensor face and at their most probable energy (approximately $800 \mathrm{keV}$ ), these betas would be expected to penetrate roughly $3 \mathrm{~mm}$ of plastic scintillator. This phenomenon would be manifested by simultaneous light output in each of the three lower layers. Conversely, the most probable beta energies from the potentially interfering radionuclides and their progeny rarely exceed $350 \mathrm{keV}$, or the associated abundances of such particles are relatively insignificant compared with the ${ }^{234 \mathrm{~m}} \mathrm{~Pa}$ betas. Hence, an unattenuated, normally incident "background" beta will generally penetrate $\leq 1 \mathrm{~mm}$. 
Gamma rays originating from the soil and surrounding materials are ubiquitous and responsible for much of the background signal associated with the sensor. Gamma-ray discrimination is possible since a charged particle will cause continuous excitations and consequent scintillation events along its entire path through the scintillator stack, while a gamma ray might produce a Compton electron in only one (indeed, if any) of the individual layers of the low- $Z$ detector material. "False positives" due to gamma-ray interactions, such as 1 ) the concurrent generation of Compton electrons in all three layers by one or more incident photons or 2) the production of a particularly energetic electron in the first layer that subsequently traverses the second and third layers is relatively rare. These phenomena are mitigated against by employing a thinner $(0.5-\mathrm{mm})$ first layer. This has the effect of approximately halving the number of gamma-induced scintillations in the first layer (compared to a 1-mm-thick ribbon), thereby decreasing the total number of "false positives" accordingly. This background reduction is accomplished with a minimal loss of efficiency for the beta particles of interest.

Also, an anti-coincidence shield above the active detector volume reduces the background signal. Cosmic-induced events (caused by charged species originating above the sensor) that penetrate the overlying anti-coincidence fiber ribbon as well as the three lower layers produce signals that are rejected by the sensor electronics. Incorporating an acrylic absorber between the triple stack and the anti-coincidence layer ensures that no energetic charged species originating from the underlying source can reach the uppermost ribbon and therefore be discarded. The light-sensitive fiber ribbons are shielded from ambient light by a thin layer of opaque plastic and the effective sensor area, which is centered on the detector base, measures approximately $30 \mathrm{~cm}$ by $60 \mathrm{~cm}$.

This detector is calibrated by observing the sensor response to soil standards that have been spiked with various amounts of ${ }^{238} \mathrm{U}$. Figure 2.1 is an example of a plot of sensor response versus uranium concentration that was generated with soils of similar composition to those characteristic of the St. Louis field area. Consequently, by simply multiplying the field-acquired sensor response by this calibration function, one is able to quantify the ${ }^{238} \mathrm{U}$ activity per gram of soil at the ground surface. Finally, it is important to note that even highly energetic beta particles are readily attenuated by soil; therefore the "depth of view" for the beta sensor is intrinsically limited, and thus this instrument should only be considered a surface-monitoring technology.

\subsection{In Situ Gamma-Ray Spectrometry}

Gamma-ray spectrometry is a well-accepted methodology for the laboratory characterization of photon-emitting materials. This technology also has many advantages as an analytical tool for environmental monitoring: 1) selective high resolution (enabling precise, quantitative, multi-radioisotopic character-ization), 2) relative ease of transport, and 3) the capability of rapid data reduction to provide essentially real-time results for field acquisitions. Its use with regard to the quantification of radionuclide content in soils, on the other hand, has been somewhat limited.

A high-purity germanium gamma-ray detector, suspended one meter from the ground in an uncollimated configuration, is sensitive to surface and subsurface activity originating from hundreds of square meters, and effectively averages any horizontal heterogeneities that may exist within its field of view. Although in theory this type of system would monitor complete $2 \pi$-space (i.e., from horizon to horizon), the actual depth and expanse of contamination detected is strictly a function of the photon energy due to geometry factors and attenuation in the soil and air. For example, approximately 80 to $90 \%$ of the total observed 


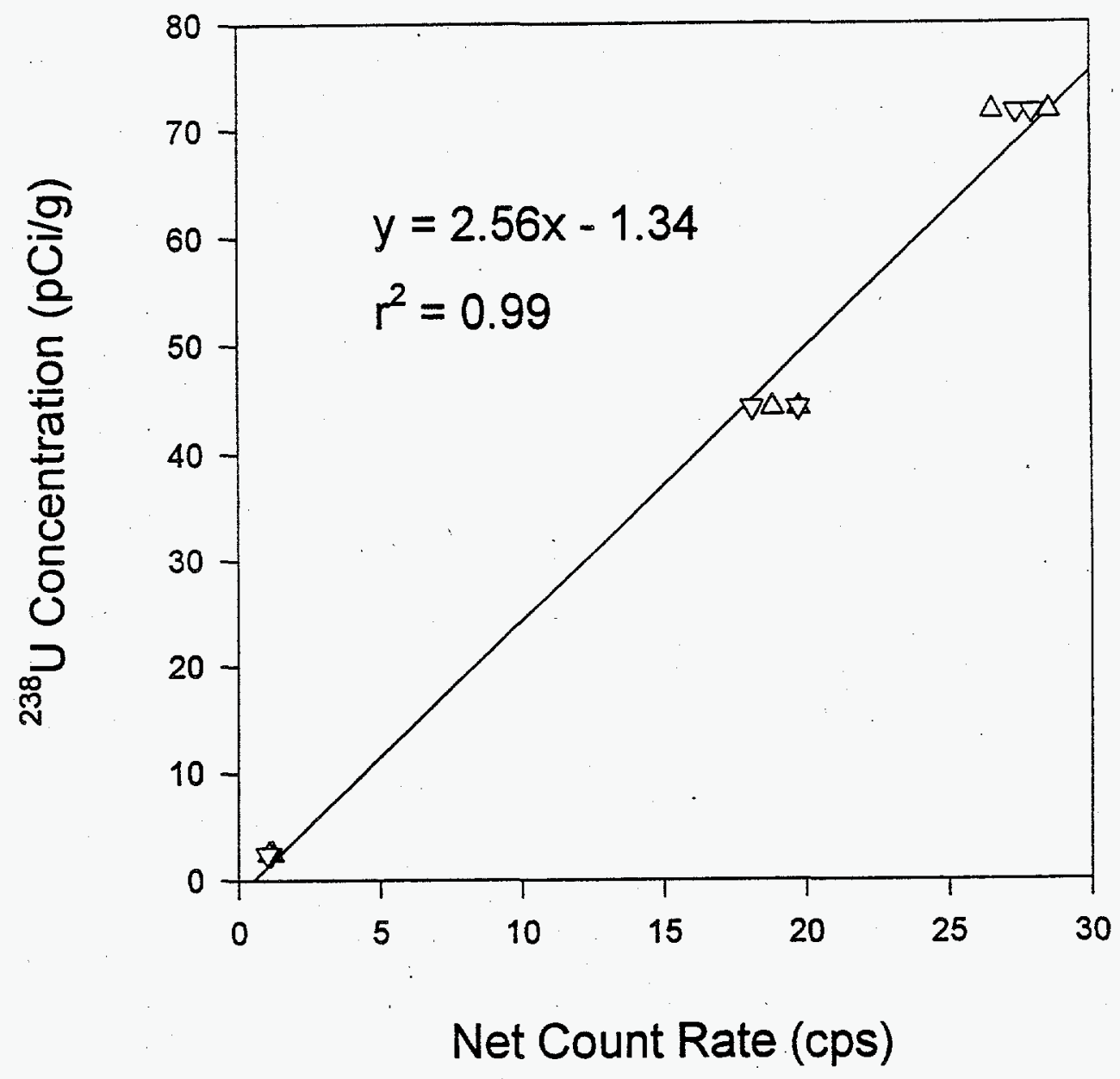

Figure 2.1. Calibration plot for ${ }^{238} \mathrm{U}$ activity in soil.

fluence originates within a 10-m radius from the detector due to geometry factors and attenuation for most gamma energies and soil distributions. A rather large surface area may be characterized, therefore, in a relatively short period of time.

In practice, photons (gammas and $\mathrm{x}$-rays) that are incident upon the germanium crystal lead to ionizations and excitations of numerous germanium atoms, thereby leading to the generation of an equivalent number of oppositely-charged species, viz., electrons (negative) and electron "holes" (positive). These charge-carrying species are swept to opposing regions of the germanium crystal due to the presence of a strong electric field where they are subsequently collected and quantified. The greater the amount of energy deposited from an event (due to the conversion of a single photon), the larger the total charge collected. Hence, by observing the magnitudes of individually collected pulses, one may determine the energies of the various photons being absorbed by the crystal. Specific photon energies serve as identifiers for various radionuclides of interest; e.g., 1.461- $\mathrm{MeV}$ gamma rays originate from the spontaneous decay of ${ }^{40} \mathrm{~K}, 0.662$ $\mathrm{MeV}$ gammas represent ${ }^{137} \mathrm{Cs}$, and $1.001-\mathrm{MeV}$ gammas are an indication of the presence of ${ }^{234 \mathrm{mPa}} \mathrm{Pa}$ daughter of ${ }^{238} U$ ). Furthermore, the total number of equivalent pulses per unit time is an indication of the 
actual amount of source material present. If secular equilibrium may be assumed (i.e., if no fractionation between $\mathrm{U}$ and $\mathrm{Th}$ or $\mathrm{Pa}$ has occurred within the past six months), then the decay rate of ${ }^{234 \mathrm{~m}} \mathrm{~Pa}$ is essentially equivalent to that of ${ }^{238} \mathrm{U}$. Consequently, one may utilize gamma-ray spectrometry to observe the rate of incidence of $1.001-\mathrm{MeV}$ gammas from ${ }^{234 \mathrm{~m}} \mathrm{~Pa}$ to determine the decay rate (and, therefore, the total activity) of ${ }^{238} \mathrm{U}$ following system calibration.

Before field deployment, the germanium gamma-ray detector must be thoroughly calibrated by observing multiple radioactive sources in various orientations. Sealed ${ }^{60} \mathrm{Co},{ }^{137} \mathrm{Cs},{ }^{241} \mathrm{Am}$, and ${ }^{152} \mathrm{Eu}$ sources are placed 1 meter from the endcap at a number of angles from the detector normal (e.g., every 10 degrees, from directly in front of the detector to directly alongside), and the sources are varied in position around the detector axis to determine its angular response function. Total gamma-ray counts for each source/orientation combination are compared with actual source strengths, and detector efficiencies for each scenario are calculated. This detector-specific information is combined with formulae that represent the gamma-ray flux originating from soils exhibiting various vertical distributions. These formulae are entirely independent of the actual detector to be calibrated and are based purely on radiation theory (gamma-ray attenuation, $1 / r^{2}$ effects, etc.) and solid geometry.

The end result of this detector-specific and detector-independent collaboration is to generate unique calibration factors, with units of (pCi/g)/(counts per second), for the radionuclides of interest. This is strictly true only for uniform vertical distributions of contaminants since the actual $\mathrm{pCi} / \mathrm{g}$ for a non-uniform distribution (e.g., one that decreases exponentially with depth) is a direct function of the depth in question. Conversely, one may assume a uniform depth distribution, despite evidence to the contrary, and obtain the "average" pCi/g for the maximum soil depth viewed (i.e., on the order of 15 to $20 \mathrm{~cm}$ for uranium, based on the $1.001-\mathrm{MeV}^{234 \mathrm{~m}} \mathrm{~Pa}$ gamma). 


\subsection{Field Results}

\subsection{High-Energy Beta Scintillation Sensor}

A prototype version of PNL's beta detector was demonstrated at the St. Louis Airport (SLAP) site over the course of three days (9/11/94 to $9 / 13 / 94)$ to characterize the uranium activity in local soils, establish the system's stability under field conditions, and evaluate the reproducibility of the sensor response for repeated measurements at identical sample locations. The sensor performed well in this regard, although the data from four individual measurements (out of a total of 75) were lost as a result of corrupted data transfers.

Background measurements were performed in the field each day to determine the local contribution from gamma-ray and cosmic-ray phenomena to the sensor response. The background count rate in the vicinity of the SLAP site (see Table 3.1) is comparable to those observed in previous field and laboratory investigations ( 5 to 6 counts per second). The slightly higher count rate recorded on $9 / 13 / 94$ is not unusual and may simply be the manifestation of a temperature inversion (or low barometric pressure), leading to an elevated radon ${ }^{(b)}$ concentration at the ground surface.

Table 3.1. Results from the daily background measurements.

\begin{tabular}{|c|c|c|c|c|}
\hline Date & Time & Acquisition Time (s) & Count Rate (cps) & lo Error (cps) \\
\hline $9 / 11 / 94$ & 0957 & 597 & 5.3 & 0.1 \\
\hline $9 / 12 / 94$ & 1521 & 1796 & 5.3 & 0.1 \\
\hline $9 / 13 / 94$ & 0919 & 600 & 6.2 & 0.1 \\
\hline
\end{tabular}

Five separate sample sites were monitored each day (viz., locations 1, 4, 5, 13, and 16). The sensor was placed directly on the ground surface, centered over the survey pins, and then situated $\sim 2$ meters to the north, east, south, and west. Individual acquisitions were of a 5-minute duration. Vegetation was cropped to a level of 10 to 15 centimeters to minimize the associated beta attenuation. Soil cores were previously collected from some of the aforementioned locations, which led to local mounds of potentially contaminated (i.e., previously buried) material.

Table 3.2 summarizes the results from the beta-sensor evaluation. Pin-number designations represent the surveyed pin (e.g., "1X") or its satellite locations ("4E", "13S", etc.). Gross, net, and average net count rates are indicated, as are the corresponding calculated ${ }^{238} \mathrm{U}$ activities and their $\mathrm{I} \sigma$ errors. The latter are measurements, essentially, of the sensor's intrasample variability.

(b) Radon-222 and its daughters originate from the decay of natural and contaminant ${ }^{238} \mathrm{U}$ and emit gammas and $\mathrm{x}$-rays that may be manifested by an increased background signal in the beta sensor. 
Table 3.2. Results from the high-energy beta scintillation sensor.

\begin{tabular}{|c|c|c|c|c|c|c|c|c|c|}
\hline \multirow{2}{*}{$\begin{array}{l}\text { Pin } \\
\text { No. }\end{array}$} & \multicolumn{3}{|c|}{ Gross Count Rate } & \multicolumn{3}{|c|}{ Net Count Rate } & \multirow{2}{*}{$\begin{array}{l}\text { Avg } \\
\text { (Net) }\end{array}$} & \multirow{2}{*}{$\begin{array}{c}{ }^{238} \mathrm{U} \\
(\mathrm{pCi} / \mathrm{g})\end{array}$} & \multirow{2}{*}{$\begin{array}{c}10 \text { Error } \\
(\%)\end{array}$} \\
\hline & Day 1 & Day 2 & Day 3 & Day 1 & Day 2 & Day 3 & & & \\
\hline $1 X$ & 312.6 & $-*$ & 307.0 & 307.2 & $\mathbf{n} / \mathbf{a}$ & 300.8 & 304.0 & 777 & 2 \\
\hline IN & 77.2 & 59.8 & 99.6 & 71.8 & 54.6 & 93.4 & 73.2 & 186 & 27 \\
\hline $1 \mathrm{E}$ & 23.4 & 24.6 & 30.2 & 18.0 & 19.4 & 24.0 & 20.4 & 51 & 15 \\
\hline is & - & 52.2 & 39.4 & $\mathrm{n} / \mathrm{a}$ & 47.0 & 33.2 & 40.1 & 101 & 13 \\
\hline $1 \mathrm{~W}$ & 38.4 & 33.4 & 53.6 & 33.0 & 28.2 & 47.4 & 36.2 & 91 & 28 \\
\hline $4 X$ & 19.6 & 18.6 & 24.4 & 14.2 & 13.4 & 18.2 & 15.2 & 38 & 17 \\
\hline $4 N$ & 34.6 & 28.4 & 43.8 & 29.2 & 23.2 & 37.6 & 30.0 & 76 & 24 \\
\hline $4 E$ & 26.0 & 30.4 & 29.6 & 20.6 & 25.2 & 23.4 & 23.0 & 58 & 10 \\
\hline $4 S$ & 14.6 & 15.0 & 12.6 & 9.2 & 9.8 & 6.4 & 8.4 & 20 & 22 \\
\hline $4 W$ & 17.8 & 14.4 & 13.2 & 12.4 & 9.2 & 7.0 & 9.6 & 23 & 29 \\
\hline $5 X$ & 107.2 & 119.6 & 138.2 & 101.8 & 114.4 & 132.0 & 116.0 & 296 & 13 \\
\hline $5 N$ & 159.8 & 156.6 & 158.0 & 154.4 & 151.4 & 151.8 & 152.6 & 389 & 1 \\
\hline $5 \mathrm{E}$ & 75.0 & 70.2 & 94.4 & 69.6 & 65.0 & 88.2 & 74.2 & 189 & 16 \\
\hline $5 \mathrm{~S}$ & 60.0 & 70.2 & 74.0 & 54.6 & 66.0 & 69.8 & 63.4 & 161 & 12 \\
\hline $5 w$ & 163.6 & 154.0 & 156.6 & 158.2 & 148.8 & 150.4 & 152.4 & 389 & 3 \\
\hline $13 X$ & 9.2 & 8.6 & 10.4 & 3.8 & 3.4 & 4.2 & 3.8 & 8 & 11 \\
\hline $13 \mathrm{~N}$ & - & 11.6 & 13.6 & $\mathrm{n} / \mathbf{a}$ & 6.4 & 7.4 & 6.9 & 16 & 12 \\
\hline $13 \mathrm{E}$ & 8.2 & 8.4 & 10.4 & 2.8 & 3.2 & 4.2 & 3.4 & 7 & 20 \\
\hline $13 \mathrm{~S}$ & 8.6 & 7.6 & 10.4 & 3.2 & 2.4 & 4.2 & 3.2 & 7 & 28 \\
\hline $13 \mathrm{~W}$ & 8.4 & 7.6 & - & 3.0 & 2.4 & $\mathbf{n} / \mathbf{a}$ & 2.7 & 6 & 17 \\
\hline $16 x$ & 119.6 & 131.0 & 113.4 & 114.2 & 125.8 & 107.2 & 115.8 & 295 & 8 \\
\hline $16 \mathrm{~N}$ & 51.2 & 61.6 & 57.6 & 45.8 & 56.4 & 51.4 & 51.2 & 130 & 10 \\
\hline $16 \mathrm{E}$ & 97.8 & 128.0 & 122.8 & 92.4 & 122.8 & 116.6 & 110.6 & 282 & 14 \\
\hline $16 \mathrm{~S}$ & 185.0 & 189.0 & 174.8 & 179.6 & 183.8 & 168.6 & 177.4 & 452 & 4 \\
\hline $16 \mathrm{~W}$ & 119.0 & 133.4 & 121.6 & 113.6 & 128.2 & 115.4 & 119.0 & 303 & 7 \\
\hline
\end{tabular}

* Data lost in transfer from buffer to storage. 
The highest uranium level was measured at pin 1 (nearly $800 \mathrm{pCi} / \mathrm{g}$ ); this may be partly because two cores were obtained at this location, and a substantial amount of contamination from depth may have been resident in the associated soil mounds. The satellite areas were also contaminated, although less so, and the relatively high level at " $1 \mathrm{~N}$ " may be due to the surface residue from a soil core taken at this location.

Sample site \#4 exhibited lower uranium activities, with levels spanning 20 to $76 \mathrm{pCi} / \mathrm{g}$. In this case, soil-core residues apparently were of no significance as location " $4 \mathrm{X}$ " had two holes (plus mounds), but only an intermediate amount of contamination $(<40 \mathrm{pCi} / \mathrm{g})$.

All locations at sample site \#5 exhibited elevated activity, with ${ }^{238} \mathrm{U}$ levels exceeding $160 \mathrm{pCi} / \mathrm{g}$ in each case. Nearly $400 \mathrm{pCi} / \mathrm{g}$ were detected at " $5 \mathrm{~N}$ " and " $5 \mathrm{~W}$ ", although, once again, soil-core residue may or may not be the cause for such enhancement. To wit, location " $5 \mathrm{X}$ " was situated near two cores/mounds, but its uranium content was intermediate with respect to its neighbors (i.e., $<300 \mathrm{pCi} / \mathrm{g}$ ).

Sample site \#13 was indicated to be representative of the local background, and this is apparently borne out in the results from the beta sensor characterization. Uranium activity averaged $\sim 7 \mathrm{pCi} / \mathrm{g}$ in this vicinity-excluding the higher content at " $13 \mathrm{~N}$ " ( $16 \mathrm{pCi} / \mathrm{g})$-and such is not uncommon for soils that display a predominantly granitic mineralogy. A minor amount of contamination at this site, however, cannot be entirely discounted.

Uranium-238 contamination was also observed at sample site \#16, where activity level's ranged from $130 \mathrm{pCi} / \mathrm{g}$ to more than $450 \mathrm{pCi} / \mathrm{g}$. Locations " $16 \mathrm{X}$ " and " $16 \mathrm{E}$ " exhibited only moderate levels of contamination $(<300 \mathrm{pCi} / \mathrm{g})$ despite the fact that two soil cores and their associated soil mounds were present.

Aside from sample " $1 X$ ", which was situated over a pair of soil cores and showed the highest amount of uranium activity, no unequivocal evidence exists for the condition in which enhanced levels are invariably associated with soil-core residues (yet this cannot be entirely discounted, either). Although all sample locations with soil-core mounds displayed elevated uranium (with the exception of "13X"), it is not certain whether such contamination originated at depth and was subsequently deposited at the surface due to the coring process, or was deposited by some other mechanism. Support for the latter possibility arises from the fact that ${ }^{238} \mathrm{U}$ contamination was observed at a number of satellite locations where no coring mounds were evident. Furthermore, it should be noted that if the activity is truly resident in the aforementioned residues, which are limited in size to a few tens of square centimeters, the observed activity for an associated measurement is likely to be underestimated as the sensor response is automatically averaged over its full window (i.e., $1800 \mathrm{~cm}^{2}$ ).

\subsection{In Situ Gamma-Ray Spectrometry}

A series of duplicate measurements were obtained at each sample site (with the exception of location \#13) using a gamma-ray sensor suspended approximately 1 meter above the ground surface. These analyses were performed on different days (between 9/10/94 and 9/13/94) to demonstrate the system's analytical reproducibility and measure any temporal variability. The results are summarized in Table 3.3. For simplicity, it was assumed that the vertical distribution of uranium activity at these locations is essentially uniform. The resulting data are, therefore, representative of the average activity in the upper 15 to 20 centimeters of soil (approximately). 
Table 3.3. Results from in situ gamma-ray spectrometry.

\begin{tabular}{|c|c|c|c|c|c|c|c|c|}
\hline $\begin{array}{c}\text { Flag } \\
\text { No. }\end{array}$ & $\begin{array}{c}\text { Day of } \\
\text { Acquisition }\end{array}$ & $\begin{array}{c}\text { Acquisition } \\
\text { Time }(\mathrm{s})\end{array}$ & $\begin{array}{c}{ }^{40} \mathrm{~K} \\
(\mathrm{pCi} / \mathrm{g})\end{array}$ & $\begin{array}{c}1 \sigma \text { Error } \\
(\%)\end{array}$ & $\begin{array}{c}{ }^{232} \mathrm{Th} \\
(\mathrm{pCi} / \mathrm{g})\end{array}$ & $\begin{array}{c}1 \sigma \text { Error } \\
(\%)\end{array}$ & $\begin{array}{c}{ }^{23} \mathrm{U} \\
(\mathrm{pCi} / \mathrm{g})\end{array}$ & $\begin{array}{c}1 \sigma \text { Error } \\
(\%)\end{array}$ \\
\hline 1 & 2 & 900 & 11 & 3 & 1 & 11 & 18 & 20 \\
\hline 1 & 3 & 900 & 12 & 3 & 1 & 11 & 16 & 23 \\
\hline 4 & 2 & 900 & 12 & 2 & 1 & 5 & $\mathrm{nd}$ & $\mathrm{n} / \mathrm{a}$ \\
\hline 4 & 3 & 900 & 12 & 2 & 1 & 6 & $\mathrm{nd}$ & $\mathrm{n} / \mathrm{a}$ \\
\hline 5 & 1 & 900 & 12 & 3 & 1 & 22 & 19 & 28 \\
\hline 5 & 4 & 300 & 12 & 6 & $\mathrm{nd}$ & $\mathrm{n} / \mathrm{a}$ & $\mathrm{nd}$ & $\mathrm{n} / \mathrm{a}$ \\
\hline 13 & 2 & 900 & 13 & 2 & 1 & 3 & 3 & 27 \\
\hline 16 & 1 & 63 & 13 & 11 & $\mathrm{nd}$ & $\mathrm{n} / \mathrm{a}$ & $\mathrm{nd}$ & $\mathrm{n} / \mathrm{a}$ \\
\hline 16 & 2 & 378 & 12 & 5 & 1 & 16 & $\mathrm{nd}$ & $\mathrm{n} / \mathrm{a}$ \\
\hline 16 & 3 & 836 & 13 & 3 & 2 & 12 & 34 & 16 \\
\hline 16 & 4 & 337 & 13 & 5 & 2 & 18 & 34 & 25 \\
\hline
\end{tabular}

* None detected.

Both ${ }^{40} \mathrm{~K}$ and ${ }^{232} \mathrm{Th}$ levels were monitored, in addition to the ${ }^{238} \mathrm{U}$ activity, to provide an internal check of the system's performance. The former are primordial in nature and, as such, have associated activity levels that are expected to remain constant regardless of sample location. As shown in Table 3.3, potassium and thorium activities $(\sim 12 \mathrm{pCi} / \mathrm{g}$ and $1 \mathrm{pCi} / \mathrm{g}$, respectively) are consistent from day to day, and the observed concentrations of these natural radionuclides are not uncommon from a global perspective (e.g., Hanford soils exhibit $15 \mathrm{pCi} / \mathrm{g}$ for ${ }^{40} \mathrm{~K}$ and $1 \mathrm{pCi} / \mathrm{g}$ for ${ }^{232} \mathrm{Th}$, respectively). Hence, these results lend confidence to the in situ results.

The lone measurement taken at location \#13, which is assumed to be representative of the local background, suggests an average ${ }^{238} \mathrm{U}$ activity of $3 \mathrm{pCi} / \mathrm{g}(1 \sigma \text { error } \approx 30 \%)^{(c)}$. This level is roughly consistent with the global average for uranium content (e.g., $\sim 1 \mathrm{pCi} / \mathrm{g}$ of ${ }^{238} \mathrm{U}$ exists in Hanford soils), although a slightly elevated concentration may be indicated. The beta-sensor results for this area support the potential for contaminant ${ }^{238} \mathrm{U}$, and since the gamma system observes a much larger area and greater depth, the betagamma combination suggests that minor surface contamination may exist in the vicinity of the flag. Such contamination would be "averaged" into the larger volume viewed by the gamma-ray sensor, thereby effectively diluting the gamma results with respect to the beta-derived concentrations.

${ }^{(c)}$ While this may be considered excessive, statistical errors can be decreased by simply counting for a longer period of time. For example, by increasing the count time to 60 minutes (not unreasonable for a field measurement), one can effectively reduce the error by a factor of two. 
Uranium activity around flag \#l averages $17 \mathrm{pCi} / \mathrm{g}$ (with a $1 \sigma$ error of $\sim 17 \%$ ), which supports evidence for ${ }^{238} \mathrm{U}$ contamination in this area. The complementary beta sensor results are indicative of substantial uranium levels here, although the combination seems to suggest that a majority of this contamination must reside on the surface and in a discrete (i.e., heterogeneous) configuration. As stated above, this type of scenario would be manifested by a gamma response that is elevated with respect to background, yet lower in magnitude to the surface beta results.

No ${ }^{238} \mathrm{U}$ was detected at flag \#4, primordial or otherwise, by the in situ gamma-ray spectrometer. This does not imply that no uranium is present at this location, but indicates that the associated acquisition time was insufficient to allow the statistical discrimination between the ${ }^{238} \mathrm{U}$-photopeak counts at $1001.0 \mathrm{keV}$ and the background signal in this region of the gamma-ray spectrum. In an actual characterization/ remediation effort, these results would direct the operator to return to this sample site and initiate an additional, longer acquisition.

Although two separate spectra were obtained at flag \#5, only one provided statistically significant results (again, a longer count time would be warranted in a true characterization effort). Average ${ }^{238} \mathrm{U}$ activity is indicated to be $19 \mathrm{pCi} / \mathrm{g}$ ( $1 \sigma$ error $\approx 26 \%$ ), and the contamination scenario is interpreted to be similar to that observed at flag \#1-in particular, a number of heterogeneous surface sources with, perhaps, some contamination in the immediate subsurface.

At flag \#16, two of the four acquisitions were viable (in terms of required count time) and mutually supportive, and these suggest that the average ${ }^{238} \mathrm{U}$ concentration here is $34 \mathrm{pCi} / \mathrm{g}$ with a $1 \sigma$ error of $\sim 6 \%$. The uranium contamination at this location may be similar in nature to that at flags \#1 and \#5 (i.e., heterogeneous and surficial), but the higher average activity indicates that the source(s) are more highly contaminated, a larger number of discrete sources are present, and/or additional activity resides at shallow depths.

As an exercise, the in situ gamma-ray spectrometer results from flag \#5 were analyzed for ${ }^{214} \mathrm{Bi}$ content $^{(\mathrm{d})}$ in an attempt to determine (to a first order) the vertical distribution of any contaminant uranium in the upper 15 to 20 centimeters of soil. Since ${ }^{214} \mathrm{Bi}$ emits a number of gamma rays (each of which experience unique and disparate degrees of attenuation in soil, such that lower-energy gamma rays are more highly attenuated), a correct assumption of a vertically homogeneous source would be manifested by calculated activities -- for each gamma ray -- that were roughly equivalent. If, on the other hand, a uniform distribution were assumed for a source that was partially shielded from the sensor (e.g., a buried source, as is expected at the SLAP site), these calculated activities would be seen to artificially increase with respect to gamma-ray energy. Figure 3.1 shows that the latter is the case at flag \#5 and, hence, the uranium contamination in this vicinity must be buried to some degree.

(d)Bismuth-214 is a multiple-gamma-emitting decay daughter of ${ }^{238} \mathrm{U}$ and may, therefore, be used as a tracer for the latter if secular equilibrium is not disturbed. 


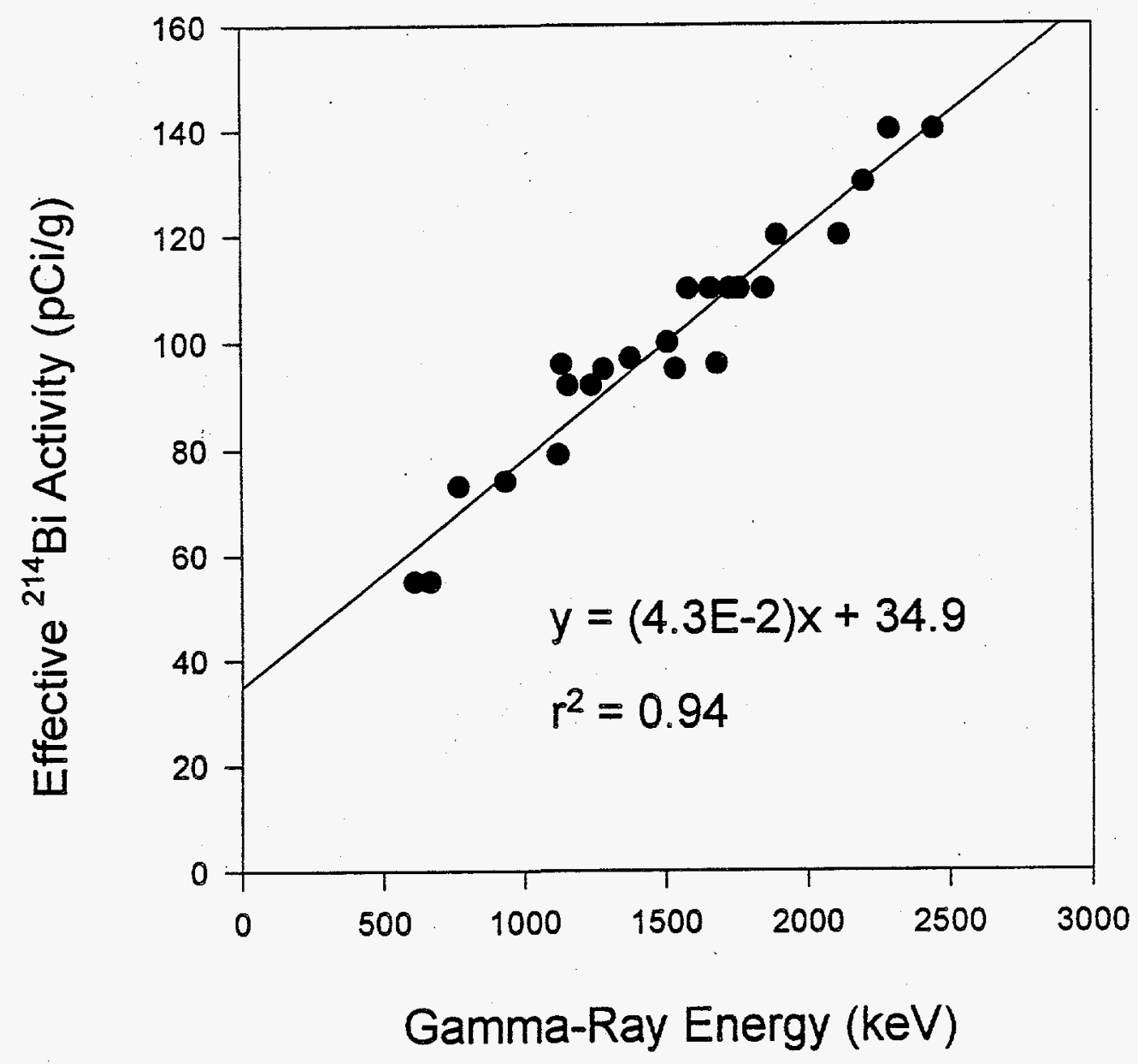

Figure 3.1. Plot of calculated ${ }^{214} \mathrm{Bi}$ activities versus associated gamma-ray energy based on the assumption of a uniformly distributed source. The monotonically increasing trend implies that the source is actually shielded from the sensor and, perhaps, is buried at this location (flag \#5).

\subsection{Laboratory Gamma-Ray Spectrometry}

A series of discrete soil samples was obtained from the ESC field crew and each aliquot ( 60 to 80 grams) was sealed in a small aluminum can for subsequent laboratory analysis via gamma-ray spectrometry. Individual samples were stored for a period of $\sim 3$ weeks (to allow the ingrowth of the radon daughters) and counted in a shielded environment for 1200 seconds. The results are summarized in Table 3.4. 
Table 3.4. Results from laboratory gamma-ray spectrometry.

\begin{tabular}{|c|c|c|c|c|c|c|c|c|}
\hline $\begin{array}{c}\text { Sample } \\
\text { No. }\end{array}$ & $\begin{array}{c}\mathrm{K}-40 \\
(\mathrm{pCi} / \mathrm{g})\end{array}$ & $\begin{array}{c}10 \text { error } \\
(\%)\end{array}$ & $\begin{array}{l}\mathrm{Th}-232 \\
(\mathrm{pCi} / \mathrm{g})\end{array}$ & $\begin{array}{c}10 \text { error } \\
(\%)\end{array}$ & $\begin{array}{c}\mathrm{U}-238 \\
(\mathrm{pCi} / \mathrm{g})\end{array}$ & $\begin{array}{c}10 \text { error } \\
(\%)\end{array}$ & $\begin{array}{l}\mathrm{Ra}-226 \\
(\mathrm{pCi} / \mathrm{g})\end{array}$ & $\begin{array}{c}10 \text { error } \\
(\%)\end{array}$ \\
\hline $1.21 \mathrm{E}$ & 19 & 5 & 9 & 4 & 12 & 22 & 12 & 4 \\
\hline $1-17 \mathrm{CD}$ & 23 & 8 & 9 & 30 & 186 & 8 & 1229 & 1 \\
\hline $1-15 D E$ & 21 & 5 & 1 & 16 & 12 & 12 & 17 & 3 \\
\hline $1-14 \mathrm{EF}$ & 13 & 5 & 1 & 14 & 45 & 4 & 4 & 7 \\
\hline $4-21 \mathrm{~A}$ & 15 & 5 & 34 & 2 & 42 & 12 & 46 & 2 \\
\hline $4-3 B C$ & 11 & 5 & 1 & 16 & 1 & 29 & 3 & 8 \\
\hline 4-3DE & 14 & 8 & 11 & 22 & 38 & 32 & 920 & 1 \\
\hline $13-4 \mathrm{~A}$ & 12 & 5 & 2 & 11 & 3 & 19 & 7 & 8 \\
\hline $13-5 B$ & 4 & 5 & 1 & 13 & 18 & 8 & 4 & 7 \\
\hline $13-5 \mathrm{D}$ & 23 & 4 & 1 & 13 & 5 & 16 & 2 & 10 \\
\hline $13-1 F$ & 14 & 5 & 1 & 11 & 19 & 8 & 3 & 9 \\
\hline $16-4 A$ & 3 & 5 & 2 & 19 & 12 & 26 & 37 & 2 \\
\hline $16-4 B$ & 28 & 8 & 14 & 18 & 152 & 6 & 1211 & 1 \\
\hline $16-14 A B$ & 11 & 6 & 6 & 24 & 48 & 19 & 387 & 1 \\
\hline $16-2 B C$ & 14 & 7 & 9 & 26 & 119 & 12 & 827 & 1 \\
\hline $16-11 B C$ & 6 & 6 & 5 & 24 & nd* & $\mathbf{n} / \mathfrak{a}$ & 179 & 1 \\
\hline $16-21 E$ & 16 & 5 & 18 & 3 & 27 & 8 & 22 & 3 \\
\hline
\end{tabular}

* None detected.

As with the field gamma-ray measurements, ${ }^{40} \mathrm{~K}$ and ${ }^{232} \mathrm{Th}$ were monitored in each sample to establish the inter-run reproducibility (recall that these natural radionuclides would not be expected to vary appreciably from sample to sample). Potassium activity is somewhat variable, although its average value (14 $\mathrm{pCi} / \mathrm{g})$ is similar to that observed in the field $(12 \mathrm{pCi} / \mathrm{g})$. The ${ }^{232} \mathrm{Th}$ content, however, varies considerably, and exhibits a higher average than that identified in the in situ phase (i.e., $7 \mathrm{pCi} / \mathrm{g}$ versus $1 \mathrm{pCi} / \mathrm{g}$ ). The reason for this difference is unknown, but may be due to heterogeneous thorium contamination or the random sampling of thorium-rich minerals.

Activity levels for ${ }^{238} \mathrm{U}$ range from $\sim 1 \mathrm{pCi} / \mathrm{g}$ to nearly $200 \mathrm{pCi} / \mathrm{g}$ in the discrete samples. The magnitudes of the uranium contents for samples $1,4,13$, and 16 are not inconsistent with those observed by the beta sensor for the same locations; hence, these data appear to be mutually supportive. The discrete measurements also seem to confirm the earlier claims of contaminant heterogeneity in the vertical and/or horizontal dimensions. 
The ${ }^{238} \mathrm{U}$ daughter, ${ }^{226} \mathrm{Ra}$, was also quantified to determine the extent of secular equilibrium between the longer-lived radionuclides of the uranium decay chain. If the condition of equilibrium was satisfied, ${ }^{238} \mathrm{U}$ and ${ }^{226} \mathrm{Ra}$ activity levels would be roughly equivalent. However, it is seen in Table 3.4 that, with one exception (sample 1-21E), disequilibrium is the norm. The radium activity is higher than that of uranium in $65 \%$ of the measured samples, and the highest ${ }^{226} \mathrm{Ra}$ concentrations are associated with ${ }^{226} \mathrm{Ra}{ }^{238} \mathrm{U}$ ratios that exceed 7:1. The reasons for this behavior are currently unknown, although such disequilibria may be due to fractionation processes of a geochemical nature (variable leaching via meteoric waters, differing retention capabilities of discrete soil horizons, etc.) that could lead to an appreciable separation of uranium and radium. 


\subsection{Conclusion}

This paper briefly discussed the theories behind in situ gamma-ray spectrometry and high-energy beta scintillation detection for characterizing radionuclide contamination in soils. Results from the field demonstrations of these methodologies were presented, as were those from subsequent laboratory measurements via gamma-ray spectrometry.

All targeted locations at the SLAP site exhibited elevated ${ }^{238} \mathrm{U}$ levels, with the possible exception of location \#13 (which is ostensibly representative of local background conditions). Such contamination is apparently heterogeneous in both the horizontal and vertical dimensions, as evidenced by 1 ) the differences observed at each location between central and satellite activities and 2) the complementary beta (surface) and gamma (surface and shallow subsurface) results, respectively. Some portion of this heterogeneity may or may not be associated with contaminated soils from depth in the form of soil-core residues at the ground surface. A buried source of uranium is suggested at location \#5, which corroborates site historical information (i.e., contaminated soils were covered with clean topfill for shielding purposes). Discrete gamma-ray measurements of sealed soil samples in a shielded laboratory configuration provided additional characterization information regarding the vertical and horizontal dimensions.

Despite the limited extent of this demonstration, the beta and gamma results were found to be mutually supportive. Both techniques detected ${ }^{238} \mathrm{U}$ contamination at the same locations, and their combination provided some insight into the spatial distribution of this radionuclide. A more detailed investigation using these methodologies is recommended for this site (or similar sites), based on a triangular map grid with a 20-m sample spacing. More accurate contaminant depth profiles could be obtained using a gamma-ray probe similar to that used in the present study yet supplied with a liquid-nitrogen reservoir suitable for downwell applications. 
PNL-10534

UC-606

\section{Distribution}

No. of

Copies

Offsite

12 DOE/Office of Scientific and Technical Information

DOE/Office of Technical

Development

A. J. Bevelo (3)

Ames Laboratory

125 South 3rd Street

Ames, IA 50010-6132

R. T. Reiman

Technical Measurements Company

2888 Bluff Street

Suite 147

Boulder, CO 80301
No. of

Copies

\section{Onsite}

14 Pacific Northwest Laboratory
A. J. Schilk (5)
C. W. Hubbard
K. H. Abel
T. W. Bowyer
Publishing Coordination
Technical Report Files (5)

Distr. 1 